\title{
A study of changing trends of maternal mortality at the tertiary care centre, MMC \& RI Mysore, India
}

\author{
Ashraf Ali M*, Babitha MC, Lokeshchandra HC, \\ Kavya D. Sharma, Maheen Zehra, Madhuri S. Reddy
}

Department of Obstetrics \& Gynaecology, Mysore Medical College and Research Institute, Mysore, Karnataka, India

Received: 07 January 2015

Accepted: 11 January 2015

\section{*Correspondence:}

Dr. Ashraf Ali M,

E-mail: dr.ashraf.vims@gmail.com

Copyright: ( $)$ the author(s), publisher and licensee Medip Academy. This is an open-access article distributed under the terms of the Creative Commons Attribution Non-Commercial License, which permits unrestricted non-commercial use, distribution, and reproduction in any medium, provided the original work is properly cited.

\begin{abstract}
Background: Maternal mortality is a reflection of the care given to women by the society. It is tragic that deaths occur during the natural process of child birth and most of them are preventable. Aims and objectives: To study the maternal mortality and the causes resulting in maternal death over 5 years in a tertiary care centre, Cheluvamba hospital, MMC \& RI, Mysore. To find out avoidable factors and use information thus generated to reduce maternal mortality.

Methods: A retrospective study of all maternal deaths from June 2008 to June 2013. All maternal deaths were reviewed and studied in detail including admission death interval and cause of death.

Results: Maternal mortality ratio ranged between 262 to $109 / 100000$ births. The causes of death were hypertensive disorders $(30.4 \%)$, haemorrhage $(24.8 \%)$, anaemia $(14.8 \%)$, sepsis $(6.8 \%)$ and others $(23.2 \%)$. Maximum deaths (70.6\%) occurred in women between $20-29$ years of age, multigravida contributed to $54.96 \%$ of maternal mortality. $42 \%$ were unbooked, $97 \%$ were referred cases.

Conclusions: Overall maternal mortality was 215/100000 live births. Maternal deaths due to direct obstetric causes were $87 \%$ and indirect were $13 \%$. The causes of potentially preventable deaths include haemorrhage, anaemia, sepsis, disseminated intravascular coagulation and its complications. Hypertensive disorders were the leading cause of death, followed by haemorrhage. Anaemia was an important indirect cause of death. Most maternal deaths are preventable by optimum utilization of existing $\mathrm{MCH}$ facilities, identifying the bottlenecks in health delivery system, early identification of high risk pregnancies and their timely referral to tertiary care centre.
\end{abstract}

Keywords: Maternal mortality, Changing trends, Hypertensive disorders, Tertiary care centre, Mysore, MDG-5

\section{INTRODUCTION}

Maternal mortality is a reflection of the care given to women by the society. It is tragic that deaths occur during the natural process of child birth and most of them are preventable. It is the young and relatively healthy women who die of various reasons. In India one maternal death is reported every $10 \mathrm{~min}^{1}$

Maternal death was defined and classified according to the World Health Organisation's International
Classification of Diseases, $10^{\text {th }}$ revision (ICD-10). "The death of a woman while pregnant or within 42 days of termination of pregnancy, irrespective of the duration and the site of the pregnancy, from any cause related to or aggravated by the pregnancy or its management but not from accidental or incidental causes." Deaths were classified as direct, indirect or fortuitous. The MMR is defined as the number of direct and indirect maternal deaths per $1,00,000$ live births up to 42 days after the termination of pregnancy. 
In recent years, increasing attention has been paid to maternal mortality trends in developing countries, especially in the context of the United Nations Millennium Declaration. The fifth Millennium Development Goal (MDG) initially articulated one target: "to reduce Maternal Mortality Ratio (MMR) by three quarters by 2015 ".

In 2012 MMR of India is 178 , which is much above the objective of 109 as per the MDG. ${ }^{4}$ More recently, a second target - to achieve universal reproductive health was added to the fifth MDG. This study analyses the causes of maternal death, highlights on the changing trends and the measures that can be taken to reach the MDG.

\section{METHODS}

A retrospective study of hospital records and death summaries of all maternal deaths at Cheluvamba hospital, Mysore over a period of 5 years i.e. from June 2008 to June 2013 were reviewed.

All maternal deaths were studied in detail with respect to maternal age, parity, booking status, delivery status, residence, referral, socioeconomic class, admission death interval and cause of death. They were studied for the immediate causes of death and the predisposing factors.

The causes were identified as direct and indirect causes. Direct obstetric deaths are those resulting from obstetric complications of the pregnant state (pregnancy, delivery, and postpartum), from interventions, omissions, incorrect treatment, or from a chain of events resulting from any of the above. Indirect obstetric deaths are those resulting from previous existing disease or diseases that developed during pregnancy, and which were not due to direct obstetric causes, rather aggravated by physiological effects of pregnancy.

Data was collected as per the prescribed proforma from the hospital records.

\section{RESULTS}

There were a total of 66,086 deliveries at Cheluvamba hospital from June 2008 to June 2013. There were 141 deaths, MMR ranged from 262 to 109 with an average of 215 . The mean age was $24.5 \pm 4.8$ years, youngest being 17 and oldest 40 year old. $10.6 \%$ were teenage pregnancies.Maternal deaths due to direct obstetric causes were $87 \%$ and indirect were $13 \%$. 74.4\% belong to the rural area, $90 \%$ were from low socioeconomic status. $88 \%$ were literate. $42.5 \%$ of them were unbooked. $97 \%$ of the cases were referred from peripheral health centres.

$29.7 \%$ died within 6 hours of admission and $21.2 \%$ died after 48 hours of admission (Figure 1).

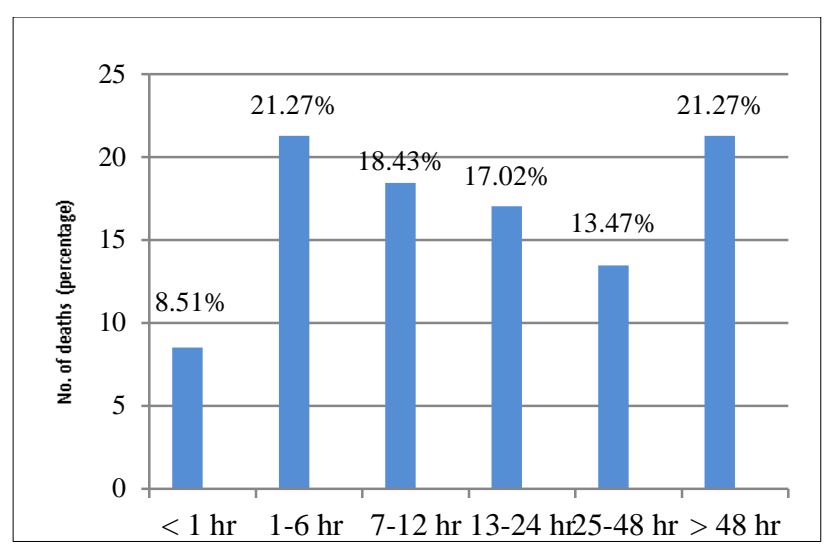

Figure 1: Admission to death interval.

$15 \%$ remained undelivered. $50 \%$ had vaginal delivery, $2.8 \%$ had instrumental delivery where as $21 \%$ underwent LSCS. Overall, the most common cause of death was hypertensive disorders $(30.4 \%)$ followed by hemorrhage $(24.82 \%)$ and anaemia is the next common cause with (14.8\%) (Figure 2).

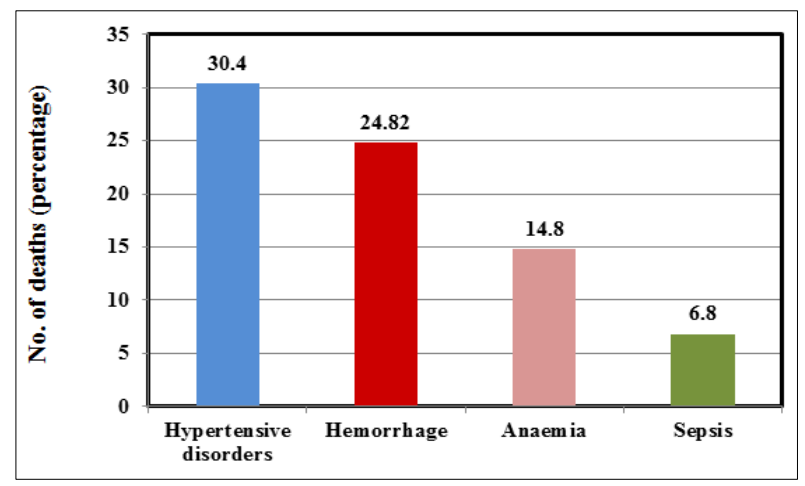

Figure 2: Cause of maternal death over 5 years.

The leading cause of death over the years has changed to hypertensive disorders from hemorrhage, making a change in trend of maternal mortality, whereas anemia remains almost a constant factor (Figure 3).

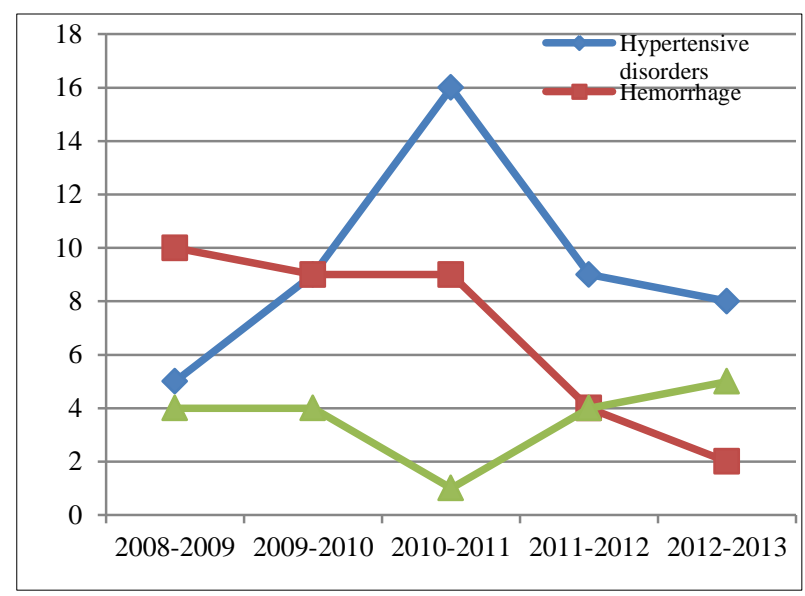

Figure 3: Changing Trends of maternal mortality. 


\section{DISCUSSION}

Evidence shows that infants whose mother die are more likely to die before reaching their second birthday than infants whose mother survive and for every women who dies 20 or more experience serious complications. What is more unfortunate is that the vast majority of deaths need not have happened and it is shocking to learn that $98 \%$ of these deaths occur in developing countries. ${ }^{5}$

Maternal Mortality is a useful indicator, not only to capture the reproductive health status of women, but also to get an idea of the richness and adequacy of maternal health services provided to women under the national programme. According to estimates by the United Nations, at current levels of fertility and mortality, 1 in 190 women in India face the risk of maternal mortality compared with 1 in 170 in Pakistan and 1 in 1400 in Sri Lanka. ${ }^{1}$

Recently, UNICEF has estimated that approximately 80 per cent of maternal deaths could be averted if women had access to essential maternity and basic health-care services. ${ }^{6}$

"The vast majority of them could have lived if they were treated equally, without discrimination and had access to the basic care we have known for over 60 years. When death is preventable, one death is one too many." United Nations Human Rights, office of the high commissioner.

In most instances, women who die in childbirth are found to have experienced at least one of the following three delays. The first delay is the delay in deciding to seek care for an obstetric complication and occurs mostly at the household level. The second delay occurs after the decision to seek care has been taken and occurs in transporting the patient from home to the health facility. The third delay is the delay in obtaining care at the facility. This is one of the most tragic issues affecting maternal survival and is a direct reflection of quality and concern with which the health facility offers emergency obstetric care to the patient.

This study was conducted at Cheluvamba hospital, a tertiary care centre, attached to Mysore medical college and research institute, Mysore district. Mysore has a population of $30,01,127^{7}$ and $98.7 \%$ of deliveries are institutional. ${ }^{8}$ Cheluvamba hospital receives referred cases from the Primary Health Centers and Community Health Centers of the nearby 5 districts of the State of Karnataka.

In our present study the MMR ranged from 262 to 109 with an average of 215.6 (Figure 4). In a study by Saini V et al., the MMR ranged from 471 to 225 at Hindu Rao hospital, Delhi. ${ }^{9}$ Tayade et al. ${ }^{10}$ reported a MMR of 242 at Wadgwa, Maharashtra, India. Shivakumar et $\mathrm{al}^{11}$ reported MMR of 974 at VIMS, Bellary, south India. Jadhav et al. ${ }^{12}$ reported MMR of 395 at Solapur tertiary care centre, India.

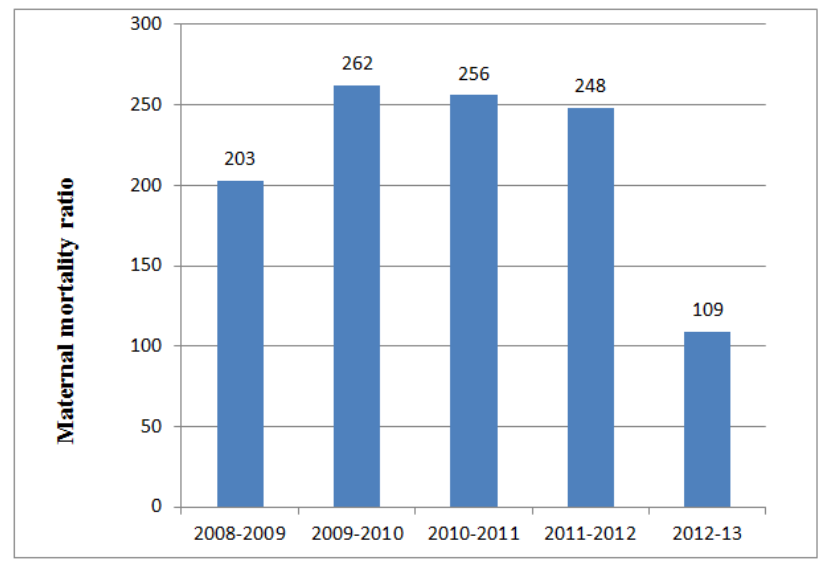

Figure 4: MMR from 2008-2009 to 2012-2013.

Among the booked cases at the centre, 3 of them had atonic PPH. The predisposing factors were anemia, nonavailability of blood products. 1 death was due to septicemia and 1 due to Amniotic fluid embolism.

Table 1 shows the MMR trends in various other studies. In a developing nation like India, haemorrhage still forms the leading cause of death. Whereas in our study, there was a change in this trend and hypertensive disorders was the most common cause like in a developed country. This calls for more importance being given to early recognition and treatment of hypertensive disorders with appropriate drugs, regular antenatal care, prevention of eclampsia and early referral.

Table 1: Comparison of maternal mortality trends.

\begin{tabular}{|c|c|c|c|c|c|}
\hline Authors & MMR & Hemorrhage \% & Toxemia \% & Sepsis \% & Anaemia $\%$ \\
\hline Vidyadhare et al. ${ }^{13} 2006-10$ & 302.6 & 21.5 & 10.52 & 7.89 & 2.63 \\
\hline Verma Ashok et al. ${ }^{14} 1995-2005$ & 345.9 & 21.8 & 20.0 & 21.6 & 15.4 \\
\hline Mukherjee et al. ${ }^{15} 1996-2006$ & 518.7 & 12.7 & 22.97 & 9.45 & 25.40 \\
\hline Prasantha $r^{16} 2005$ & 625 & 9.22 & 50.56 & 18.17 & 4.8 \\
\hline Puri et al. ${ }^{17} 2003-06$ & 690 & 12 & 18 & 24 & 13 \\
\hline Present study 2008-2013 & 215.6 & 24.8 & 30.4 & 6.3 & 14.8 \\
\hline
\end{tabular}


$10.6 \%$ of the MMR in our study occurred in the age group less than 20 , indicating that teenage pregnancies have high risk of maternal mortality. $90 \%$ belong to low socioeconomic strata. Most of the deaths occurred within 6 hours of admission and after 48 hours, highlighting the need for an early referral and improving the critical care facilities by increasing the manpower and optimizing workload at the tertiary centre. Anemia still is a major indirect cause of death, preconceptional anaemia correction and better antenatal care is required to prevent this. It also presses the need for the availability of blood and blood products. Septic abortion was the cause of death in 4 of our patients, safe abortion services to be strengthened to prevent this.

\section{CONCLUSION}

Most maternal deaths are preventable by optimum utilization of existing $\mathrm{MCH}$ facilities, identifying the bottlenecks in health delivery system, early identification of high risk pregnancies and their timely referral to a tertiary care centre. The quality of antenatal care should be improved and also hospitals should be equipped with better infrastructure, manpower, ICU care and blood bank facilities so as to reduce the maternal mortality and reach the MDG-5.

\section{ACKNOWLEDGEMENTS}

The authors are thankful to all the people who have helped in bringing out this paper, especially, Dr. Radhamani, Medical Superintendent, Cheluvamba Hospital, staff of medical records department and of course our families for all their support.

\section{Funding: No funding sources}

Conflict of interest: None declared

Ethical approval: Not required

\section{REFERENCES}

1. WHO. Trends in maternal mortality, 1990-2013. WHO, UNICEF, UNFPA, the World Bank and the United Nations Population Division Estimates, 2014. Available at: http://apps.who.int/iris/bitstream/10665/112682/2/9789241 507226_eng.pdf.

2. World Health Organization. Health statistics and information systems, 2014. Available at: http://www.who.int/healthinfo/statistics/indmaternalmortal ity/en/. Accessed 5 January 2015.

3. Ahmed Abdella. Maternal mortality trend in Ethiopia. Ethiop J Health Dev 2010;24(1):115-22.

4. Sample Registration System, Office of Registrar General, India. Special bulletin on maternal mortality in India 201012, December 2013. Available at:
http://www.censusindia.gov.in/vital_statistics/SRS_Bulleti ns/MMR_Bulletin-2010-12.pdf.

5. Nishu Priya, Verma Ashok, Verma Suresh. Maternal mortality: ten years retrospective study. J Med Educ Res. 2010 Jul-Sep;12(3):134-6.

6. UNICEF. The state of the world's children 2009: maternal and newborn health. In: UNICEF, eds. Sales No. E.09.xx.1. India: United Nations Publication; 2010: 2.

7. Mysore. Mysuru district, Taluk wise population of mysore district as per 2011 census, 2012. Available at: http://www.mysore.nic.in/population.htm. Accessed 5 January 2015.

8. IIPS and Ministry of Health and Family Welfare, Government of India. Mysore district fact sheet (20122013), District Level Health Survey-4, 2014. Available at: https://nrhm-mis.nic.in.

9. Saini V, Gupta M. Review of maternal mortality in an urban tertiary care hospital of north India. Int J Basic Appl Med Sci. 2014 Jan-Apr;4(1):59-64.

10. Surekha Tayade, Madhuri Bagde, Poonam V. Shivkumar, Atul Tayade, Nilajkumar Bagde. Maternal death review to know the determinants of maternal mortality in a district hospital of Central India. Int $\mathrm{J}$ Biomed Res. 2012;3(03):157-63.

11. Shivakumar HC, Umashankar KM, Ramaraju HE, Shankar J. Analysis of maternal mortality in tertiary care hospital, Vijaya Nagara institute of medical sciences, Bellary, South India. Int J Basic Appl Medn Sci. 2013 MayAug;3(2):237-42.

12. Jadhav CA, Gavandi Prabhakar, Shinde MA, Tirankar VR. Maternal mortality: five year experience in tertiary care centre. Indian J Basic Appl Med Res. 2013 June;2(7):7029.

13. Vidhyadhar B, Purushottam A, Giri B, Garg RC. Maternal mortality at a tertiary care teaching hospital of rural India, a retrospective study. Int J Biol Med Res. 2011;2(4):10436.

14. Verma A, Minhas S, Sood A. A study on maternal mortality in Dr. Rajendra Prasad Govt. M.C. Tanda Dist. Kangra, H.P. (Jan. 1999-Dec. 2005). Indian J Obstet Gynaecol. 2008;58(3):226-9.

15. Mukherjee S, Theengh C, Bhattacharya S, Maru L. Maternal mortality at a tertiary care institute of central India. Asian J Obstet Gynaecol Pract. 2010;4:23-7.

16. Pal A, Prasantha R, Samir H, Mondal TK. Review of changing trends in maternal mortality in a rural medical college of West Bengal. J Obstet Gynaecol India. 2005;55(6):521-4

17. Puri A, Yadav I, Jain N. Maternal mortality in an urban tertiary care hospital of North India. Indian $\mathrm{J}$ Obstet Gynaecol. 2011;61(3):280-5.

DOI: $10.5455 / 2320-1770 . i j \operatorname{rog} 20150243$

Cite this article as: Ashraf Ali M, Babitha MC, Lokeshchandra HC, Sharma KD, Zehra M, Reddy MS. A study of changing trends of maternal mortality at the tertiary care centre, MMC \& RI Mysore, India. Int J Reprod Contracept Obstet Gynecol 2015;4:239-42. 